\title{
Phytoestrogens Enhance the Vascular Actions of the Endocannabinoid Anandamide in Mesenteric Beds of Female Rats
}

\author{
Roxana N. Peroni, ${ }^{1}$ Tamara Abramoff, ${ }^{1}$ Isabel Neuman, ${ }^{2}$ \\ Ernesto J. Podestá, ${ }^{2}$ and Edda Adler-Graschinsky ${ }^{1}$ \\ ${ }^{1}$ Instituto de Investigaciones Farmacológicas, Consejo Nacional de Investigaciones Científicas y Técnicas, Universidad de Buenos Aires, \\ Junin 956, $5^{\circ}$ Piso, C1113AAD Buenos Aires, Argentina \\ ${ }^{2}$ Departamento de Bioquímica IIMHNO, Facultad de Medicina, Universidad de Buenos Aires, Paraguay 2155, $5^{\circ}$ Piso \\ C1121ABG Buenos Aires, Argentina
}

Correspondence should be addressed to Roxana N. Peroni, rperoni@ffyb.uba.ar

Received 25 February 2011; Revised 12 October 2011; Accepted 12 October 2011

Academic Editor: Zafar Israili

Copyright ( $) 2012$ Roxana N. Peroni et al. This is an open access article distributed under the Creative Commons Attribution License, which permits unrestricted use, distribution, and reproduction in any medium, provided the original work is properly cited.

In rat isolated mesenteric beds that were contracted with NA as an in vitro model of the vascular adrenergic hyperactivity that usually precedes the onset of primary hypertension, the oral administration (3 daily doses) of either $10 \mathrm{mg} / \mathrm{kg}$ genistein or $20 \mathrm{mg} / \mathrm{kg}$ daidzein potentiated the anandamide-induced reduction of contractility to NA in female but not in male rats. Oral treatment with phytoestrogens also restored the vascular effects of anandamide as well as the mesenteric content of calcitonin gene-related peptide (CGRP) that were reduced after ovariectomy. The enhancement of anandamide effects caused by phytoestrogens was prevented by the concomitant administration of the estrogen receptor antagonist fulvestrant $(2.5 \mathrm{mg} / \mathrm{kg}$, s.c., 3 daily doses). It is concluded that, in the vasculature of female rats, phytoestrogens produced an estrogen-receptor-dependent enhancement of the anandamidevascular actions that involves the modulation of CGRP levels and appears to be relevant whenever an adrenergic hyperactivity occurs.

\section{Introduction}

Endocannabinoids contribute to reduce vascular contractility under pathological conditions where vascular responsiveness is altered. Hence, compounds that selectively modulate the action as well as the levels of endocannabinoids represent templates for potential new therapeutic strategies [1]. In this sense, the exogenous administration of the endocannabinoid anandamide is known to induce the decrease of blood pressure in spontaneously hypertensive rats [2] as well as in Wistar rats fed with a high-salt diet [3]. Inhibition of the fatty acid amide hydrolase, enzyme involved in intracellular anandamide degradation, normalizes the cardiovascular function in hypertensive rats without producing adverse metabolic effects [4]. Estrogens are also positive modulators of the anandamide effects at the vascular wall since they stimulate the release of anandamide from human endothelial cells [5] as well as potentiate the anandamideinduced vasorelaxations by increasing the bioavailability of the calcitonin-related peptide (CGRP) in the rat mesenteric vasculature [6]. This potent vasodilator peptide is released, at least in part, as a consequence of the activation of the transient receptor potential vanilloid type 1 (TRPV1) by anandamide [7].

Phytoestrogens, such as genistein and daidzein, are able to activate estrogen receptors which confer to them weak estrogen-like activity [8]. They are associated with a favorable cardiovascular risk profile [9] and therefore constitute an interesting food-based alternative to the hormone replacement therapy during the menopausal transition in women [10]. Since in a variety of rat cell lines phytoestrogens inhibit anandamide uptake by blocking the fatty acid amide hydrolase [11], it is possible that phytoestrogens also regulate the vascular effects of anandamide. Hence, the aim of the 
present study was to elucidate whether oral administration of the soy-derived phytoestrogens genistein and daidzein modulates the anandamide-induced reductions of the contractions to NA in the rat isolated mesenteric bed that was used as an in vitro model of the adrenergic hyperactivity that usually precedes the onset of primary hypertension [12].

The hypothesis is that the endocannabinoid system could be another target, in addition to nitric oxide, prostanoids, and antioxidant defense genes, for the beneficial cardiovascular actions proposed for phytoestrogens $[13,14]$.

\section{Materials and Methods}

2.1. Animals. Male and female Sprague-Dawley rats were housed under a 12:12 h light: dark cycle, at controlled room temperature with food and water ad libitum. Experiments were conducted in accordance to the Guide for the Care and Use of Laboratory Animals of the National Research Council (USA, 1996). Adult female rats (8-10 weeks, 165-200 g body weight) were either bilaterally ovariectomized (OVX) or sham-operated through dorsal incision, under anaesthesia (40-60 mg/kg ketamine hydrochloride $+10 \mathrm{mg} / \mathrm{kg}$ xylazine hydrochloride). After 21 days of endogenous hormonal decline, the animals were randomly allocated to either drugtreated or vehicle-treated groups.

2.2. Animal Treatments. Dose and duration of treatment with phytoestrogens were selected on the basis that they reverted partially, but significantly the uterine atrophy caused by ovariectomy that is considered a parameter of estrogenic activity [15]. According to this, genistein $(10 \mathrm{mg} / \mathrm{kg})$ or daidzein $(10-20 \mathrm{mg} / \mathrm{kg}$ ) was administered by oral gavage (p.o.) once daily during three days. Drugs were dissolved in dimethylsulfoxide (residual concentration $<1 \%$ ) and were diluted in corn oil. Some intact as well as OVX female rats treated with phytoestrogen received concomitant subcutaneous administrations of the estrogen receptor antagonist $2.5 \mathrm{mg} / \mathrm{kg}$ fulvestrant (ICI 182,780) dissolved in ethanol and diluted in corn oil. All groups were analyzed by comparison with the corresponding vehicle-treated animals.

2.3. Mesenteric Vascular Bed Preparation. Adult male (250$350 \mathrm{~g})$ and female (230-350 g) Sprague-Dawley rats were anaesthetized with urethane $\left(1.2 \mathrm{~g} \mathrm{~kg}^{-1}\right.$ body weight), the abdomen was opened, and the mesenteric vascular bed was cannulated and removed according to [16]. The isolated mesenteric bed was transferred to a perspex chamber and perfused with the Krebs solution at $37^{\circ} \mathrm{C}$ bubbled with $95 \%$ $\mathrm{O}_{2}$ plus $5 \% \mathrm{CO}_{2}$ at a constant flow rate of $2 \mathrm{~mL} / \mathrm{min}$, maintained by a peristaltic pump. Changes in vascular resistance were measured as changes in perfusion pressure and recorded through a Statham pressure transducer connected to a Grass polygraph. Up to nine consecutive, $20 \mathrm{~min}$ apart bolus injections of noradrenaline (NA) were performed in one preparation because the short contractile responses induced by this drug are highly reproducible. On the contrary, the sustained contractions that are obtained whenever the
TABLE 1: Noradrenaline-induced contractions.

\begin{tabular}{lcc}
\hline Group & $n$ & $\begin{array}{c}\text { NA-induced contraction } \\
(\mathrm{mm} \mathrm{Hg})\end{array}$ \\
\hline Male rats & & $51.39 \pm 8.46$ \\
Control & 6 & $52.50 \pm 4.72$ \\
Vehicle for phytoestrogens & 7 & $43.75 \pm 6.38$ \\
$10 \mathrm{mg} / \mathrm{kg}$ genistein & 4 & $62.5 \pm 9.68$ \\
$10 \mathrm{mg} / \mathrm{kg}$ daidzein & 5 & \\
\hline Intact female rats & & $53.54 \pm 8.08$ \\
Control & 6 & $47.68 \pm 6.67$ \\
Vehicle for phytoestrogens & 5 & $51.88 \pm 4.72$ \\
$10 \mathrm{mg} / \mathrm{kg}$ genistein & 4 & $55.42 \pm 5.02$ \\
$10 \mathrm{mg} / \mathrm{kg}$ daidzein & 6 & $53.80 \pm 1.70$ \\
$20 \mathrm{mg} / \mathrm{kg}$ daidzein & 5 & $52.81 \pm 3.61$ \\
\hline Ovariectomized female rats & & $41.25 \pm 6.49$ \\
Control & 8 & $43.76 \pm 4.55$ \\
Vehicle for phytoestrogens & 4 & $56.25 \pm 11.48$ \\
Vehicle for 17 $\beta$-oestradiol & 6 & $55.00 \pm 8.42$ \\
$10 \mathrm{mg} / \mathrm{kg}$ genistein & 4 & $47.50 \pm 4.50$ \\
$10 \mathrm{mg} / \mathrm{kg}$ daidzein & 4 & $52.50 \pm 9.64$ \\
$20 \mathrm{mg} / \mathrm{kg}$ daidzein & 4 & 6
\end{tabular}

agonists are added to the perfusate are difficult to reproduce in the same preparation [17].

Table 1 shows that the contractile responses to NA in the mesenteric bed had similar magnitudes between the groups (e.g., males and intact and ovariectomized females). Moreover, phytoestrogen treatment did not modify per se either the basal tone or the reactivity to NA; respect to the vehicle-treated groups.

To evaluate anandamide-induced effect, after the first NA bolus injection considered as control, cumulative anandamide concentrations were perfused during $20 \mathrm{~min}$, and the responsiveness to NA (a submaximal pressor effect, i.e., 40 to $60 \mathrm{~mm} \mathrm{Hg}$ ) was challenged on every one concentration. Anandamide was dissolved in ethanol $(<0.1 \%)$, and further dilutions were made in the Krebs solution. No effects on basal tone of mesenteries isolated from either male or female rats were observed for any concentration of anandamide.

2.4. Immunohistochemistry for CGRP. The experiments were performed according to [6]. Deeply anaesthetized rats were fixed by transcardiac perfusion with PBS containing 4\% w/v paraformaldehyde, and mesenteric vascular beds were dissected. The endogenous peroxidase activity was blocked with $1 \% \mathrm{H}_{2} \mathrm{O}_{2}$, and the preparations were permeabilized with $0.2 \%$ Triton X-100. Overnight incubation at room temperature with 1/3,000 anti-CGRP antibody (Sigma Aldrich, St. Louis, MI, USA) and $1 \mathrm{~h}$ incubation with $1 / 200$ goat anti-rabbit peroxidase conjugated antibody (Sigma Aldrich, St. Louis, MI, USA) were performed. Several branches of each mesenteric bed were not incubated with the primary antibody to obtain the corresponding controls. Peroxidase 


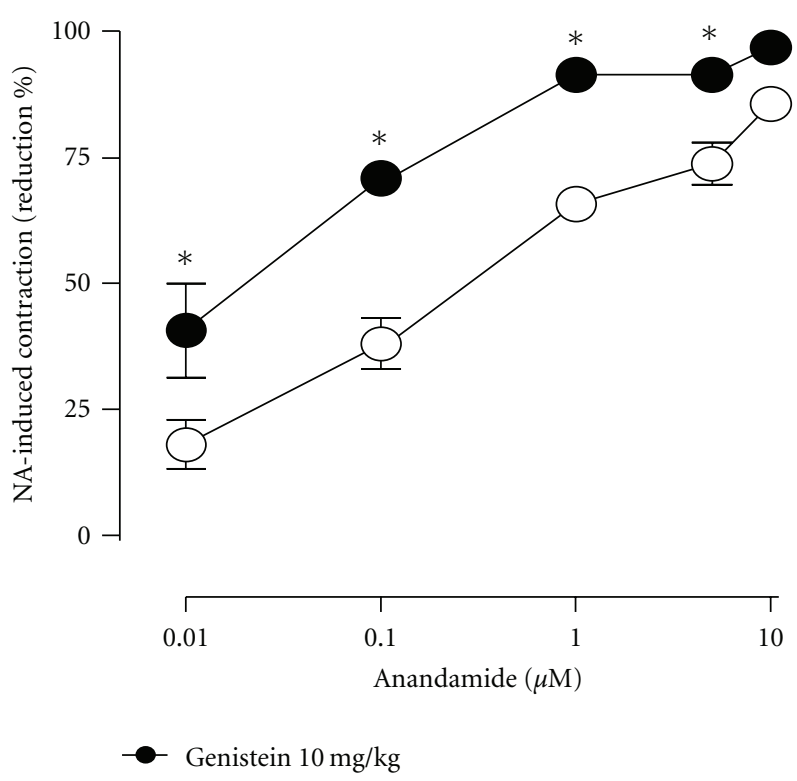

(a)

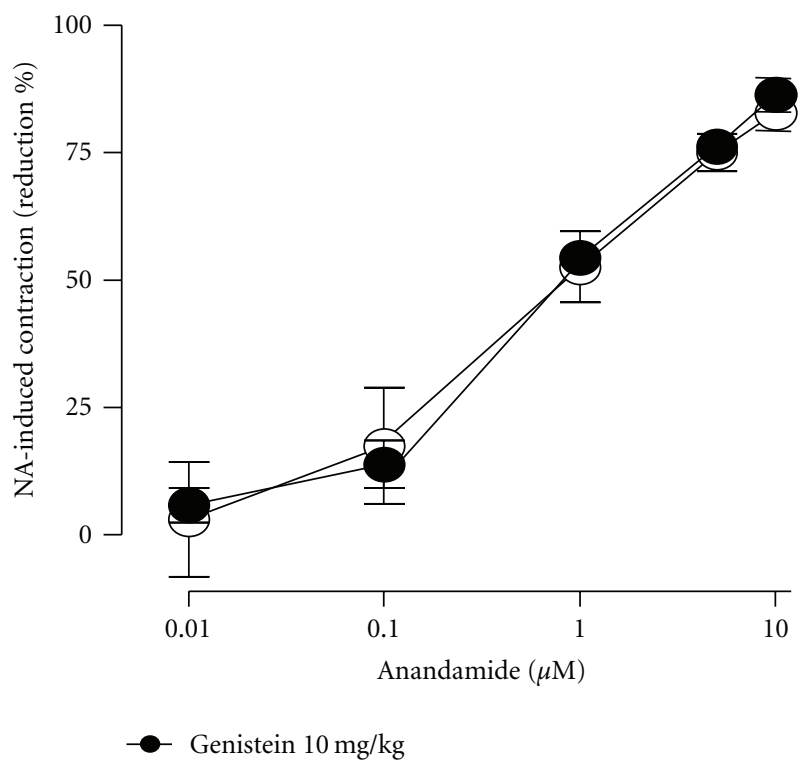

(b)

Figure 1: Effects of 3-day oral administration of $10 \mathrm{mg} / \mathrm{kg}$ genistein (filled circles) on anandamide-induced reductions of contractile responses to NA in mesenteric vascular beds isolated from female (a) as well as male (b) rats. Vehicles are depicted in open circles. ${ }^{*} P<0.05$ when treatment with genistein was compared to the corresponding vehicle.

activity was evidenced with diaminobenzidine in an Eclipse $50 i$ NIKON light microscope equipped with a video camera Nikon DS-SM. All groups were simultaneously processed to prevent interassay differences. CGRP-immunoreactive fibers were quantified in second arterial branches. Relative area (stained/total area) per field and the difference between anti-CGRP-incubated tissues and the corresponding controls were measured. Morphometric analysis was performed with Image J software (1.34 S National Institutes of Health USA).

2.5. Drugs. (-)-Noradrenaline bitartrate, genistein, and daidzein were obtained from Sigma-Aldrich (St Louis, MI, USA). Fulvestrant (Faslodex) was kindly donated by Astra Zeneca. Anandamide was purchased from Cayman Chemical (Ann Arbor, MI, USA).

2.6. Statistical Analysis. Data are presented as the mean \pm SEM ( $n=4$ to 6$)$ of the percent reductions of the initial contraction to NA and were analyzed by two-way analysis of variance followed by Bonferroni's post hoc t-test. Oneway analysis of variance followed by Dunnett's multiple comparison tests were performed for the immunohistochemical assays as well as for noradrenaline-induced contractions. In all the cases, a $P<0.05$ was considered as significant.

\section{Results}

As shown in Figure 1, the endocannabinoid anandamide reduced, in a concentration-dependent manner, the transient contractions elicited by $10 \mathrm{nmol}$ NA in mesenteric beds isolated from either male or female Sprague-Dawley rats. The oral administration of the phytoestrogen genistein
( $10 \mathrm{mg} / \mathrm{kg}$; daily during 3 days) significantly potentiated the effect of anandamide in mesenteric beds isolated from female but not from male mesenteric beds.

In turn, a 3-day treatment with the soy-derived phytoestrogen daidzein did not modify the anandamide-induced reduction of contractile responses when administered at a dose of $10 \mathrm{mg} / \mathrm{kg}$ to either female (Figure 2(a)) or male rats (Figure 2(b)) but did significantly increase the anandamide effects in mesenteries isolated from female rats when dose was scaled up to $20 \mathrm{mg} / \mathrm{kg}$ (Figure 2(c)).

The oral administration of the phytoestrogen genistein ( $10 \mathrm{mg} / \mathrm{kg}$; daily during 3 days) significantly potentiated the effect of anandamide in mesenteric beds isolated from female but not from male mesenteric beds.

Twenty-one days after ovariectomy, the ability of anandamide to decrease the contractile response to NA in mesenteric arteries declined significantly (compare intact females in Figure 1 and untreated OVX females in Figure 3; $P<0.001$ ). Figure 3 shows that a 3-day treatment with either $10 \mathrm{mg} / \mathrm{kg}$ genistein or $20 \mathrm{mg} / \mathrm{kg}$ daidzein could restore anandamide-induced vascular effects in OVX rats. On the other hand, no effects were evidenced by treatment with $10 \mathrm{mg} / \mathrm{kg}$ daidzein (Figure 3(b)).

The estrogen receptor antagonist fulvestrant (2.5 $\mathrm{mg} \mathrm{kg}^{-1}$, s.c. during 3 days) did not modify per se the anandamide-induced reductions of precontracted arteries either in intact (Figure 4(a)) or in OVX (Figure 5(a)) females rats but significantly prevented the potentiation on anandamide-induced effects caused by either $10 \mathrm{mg} / \mathrm{kg}$ genistein or, $20 \mathrm{mg} / \mathrm{kg}$ daidzein in intact (Figures 4(b) and $4(\mathrm{c})$ ) as well as in OVX female rats (Figures 5(b) and 5(c)). As shown in Figure 6, the density of the CGRP-containing fibers surrounding mesenteric arteries was markedly reduced 


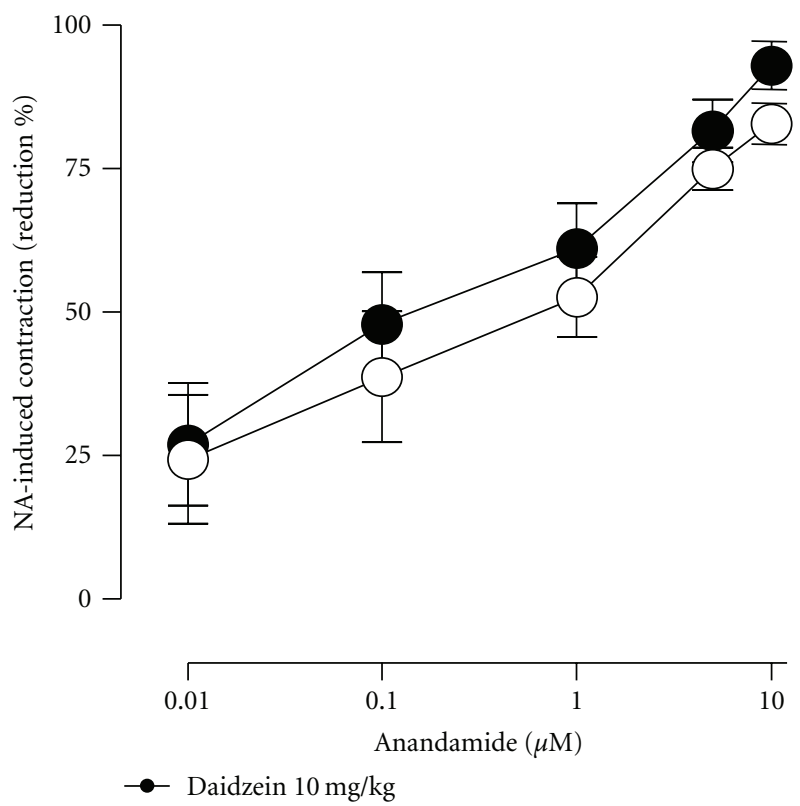

(a)

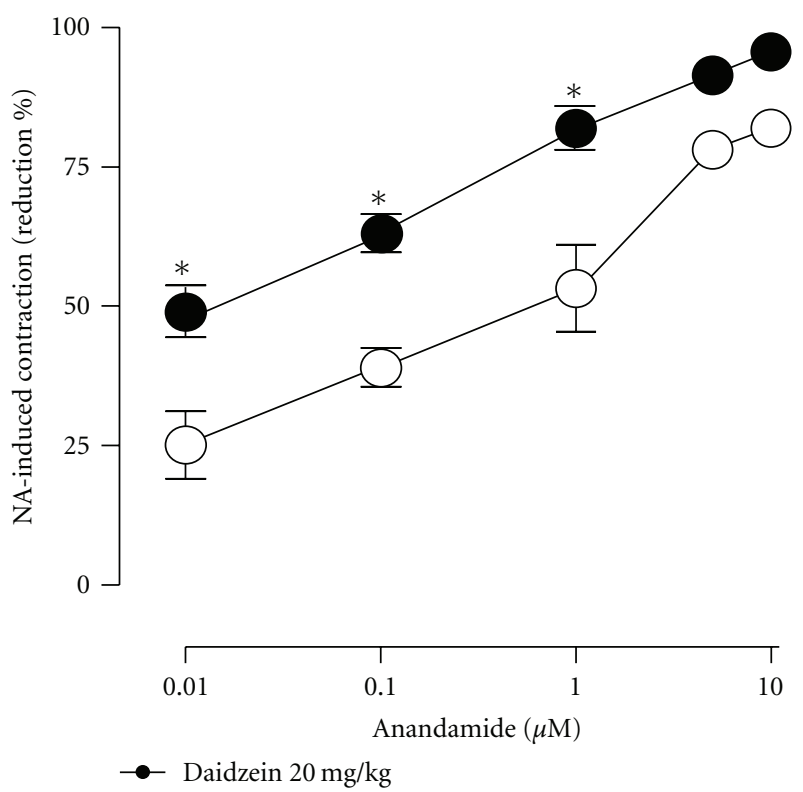

(c)

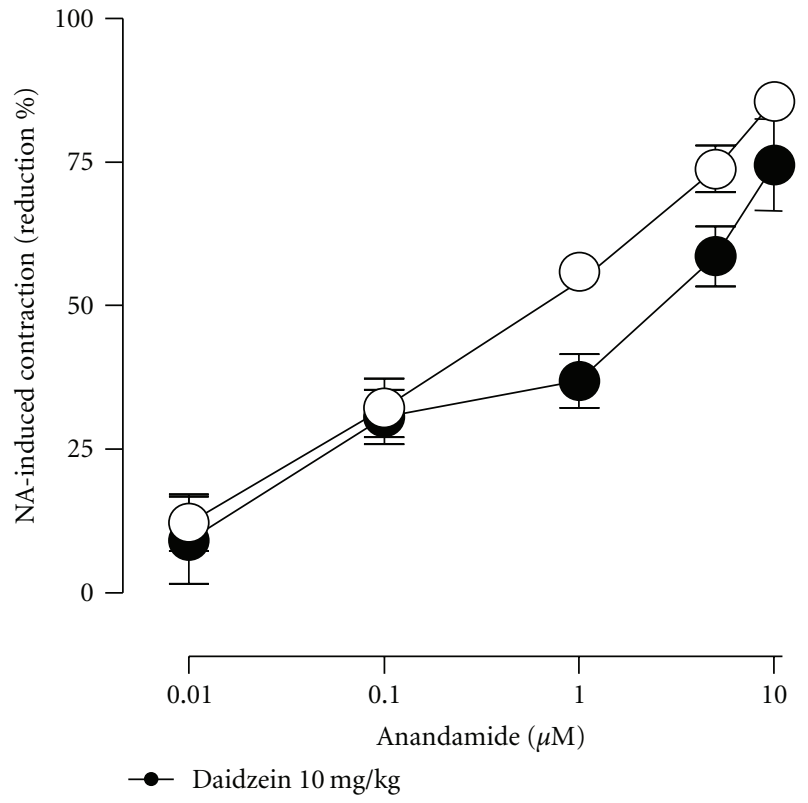

(b)

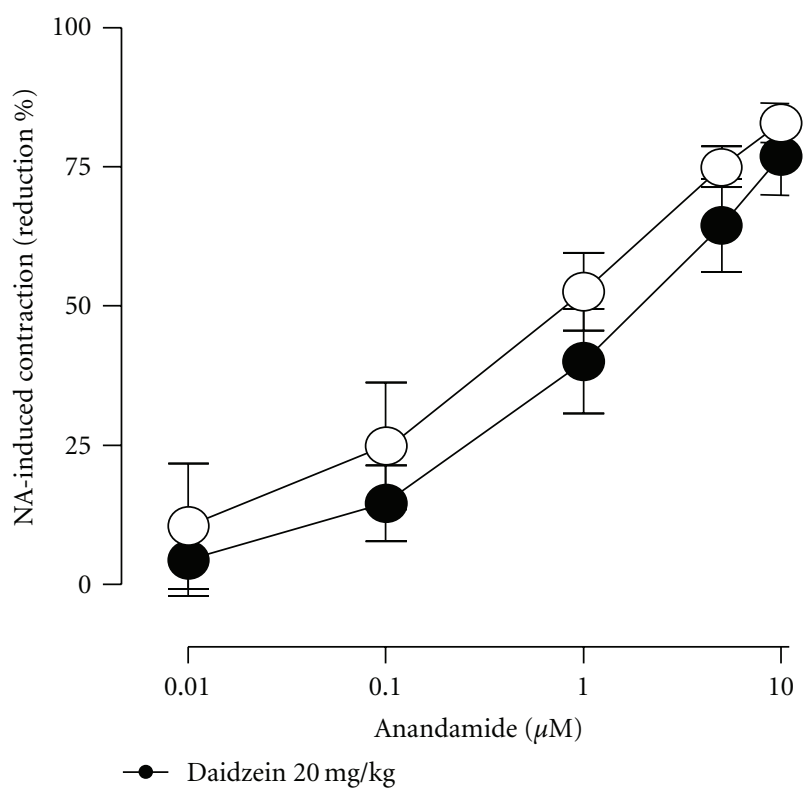

(d)

FIGURE 2: Effects of 3-day oral administration of either $10 \mathrm{mg} / \mathrm{kg}$ or $20 \mathrm{mg} / \mathrm{kg}$ daidzein (filled circles) on anandamide-induced reductions of contractile responses to NA in mesenteric vascular beds isolated from female (a) and (c) as well as male (b) and (d) rats. Vehicles are depicted in open circles. ${ }^{*} P<0.05$ when treatment with daidzein was compared to the corresponding vehicle.

by ovariectomy and significantly restored after a 3-day oral treatment with $10 \mathrm{mg} / \mathrm{kg}$ genistein. Moreover, when animals were concomitantly treated with genistein and fulvestrant, the enhancing effect of genistein was not observed. A similar profile was found after a 3-day oral treatment with $20 \mathrm{mg} / \mathrm{kg}$ but not with $10 \mathrm{mg} / \mathrm{mg}$ daidzein (Figure 7 ).

\section{Discussion}

The present study shows that oral administration of the soyderived phytoestrogens genistein and daidzein daily during
3 days enhanced the decrease in the contractile responses to NA induced by anandamide in mesenteric arteries isolated from female but not from male rats. Taking into account that the anandamide effect is already greater in female mesenteries compared to males [16], the enhancing effect of the phytoestrogens shown here in female rats adds to the overall sex differentiation in this model. The tissue was selected because it represents a group of resistance vessels that greatly contributes to the maintenance of the total peripheral vascular resistance $[17,18]$. Precontractions to NA were used to resemble the effects of the adrenergic 

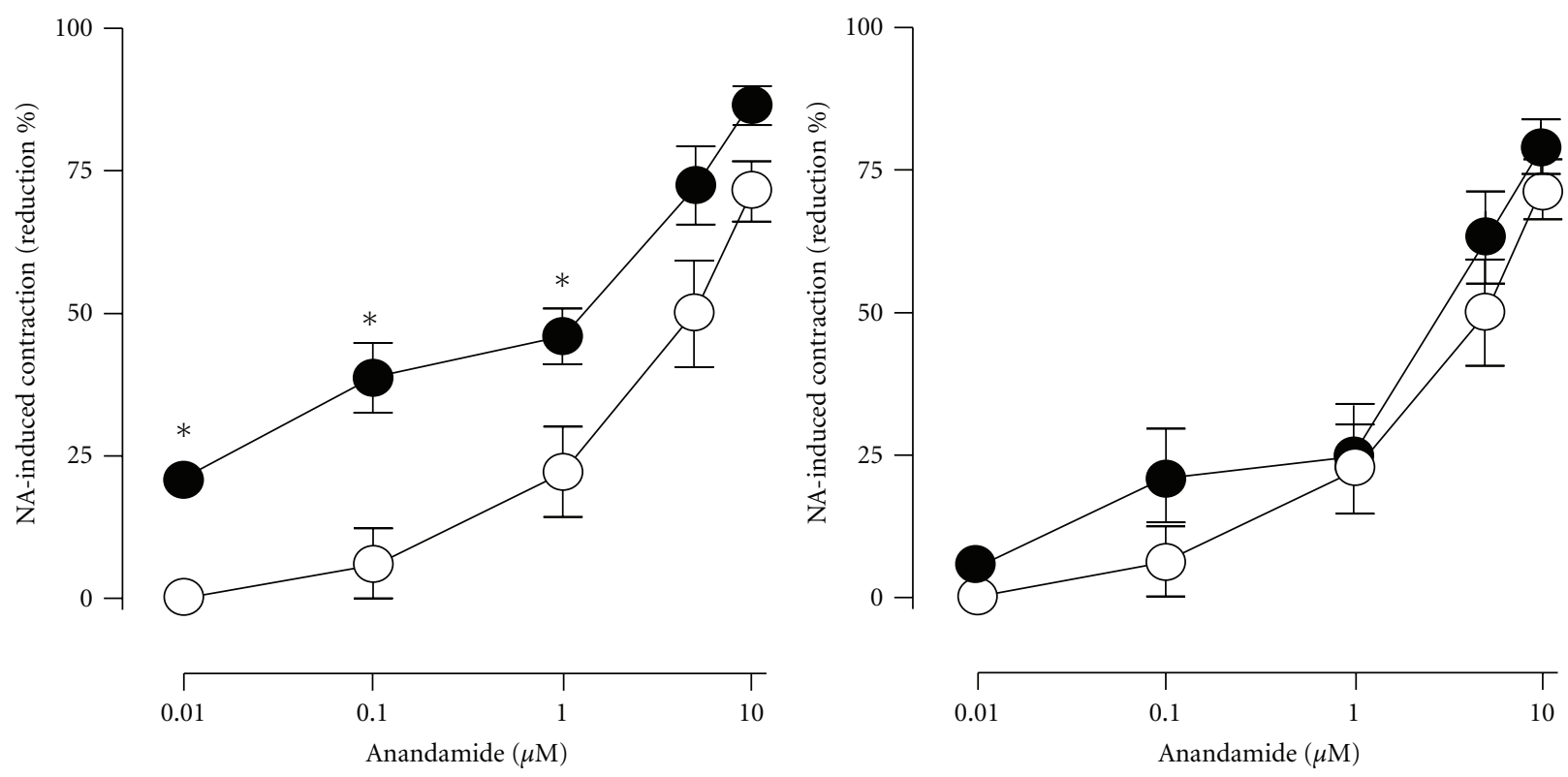

$10 \mathrm{mg} / \mathrm{kg}$ genistein

$10 \mathrm{mg} / \mathrm{kg}$ daidzein

(a)

(b)

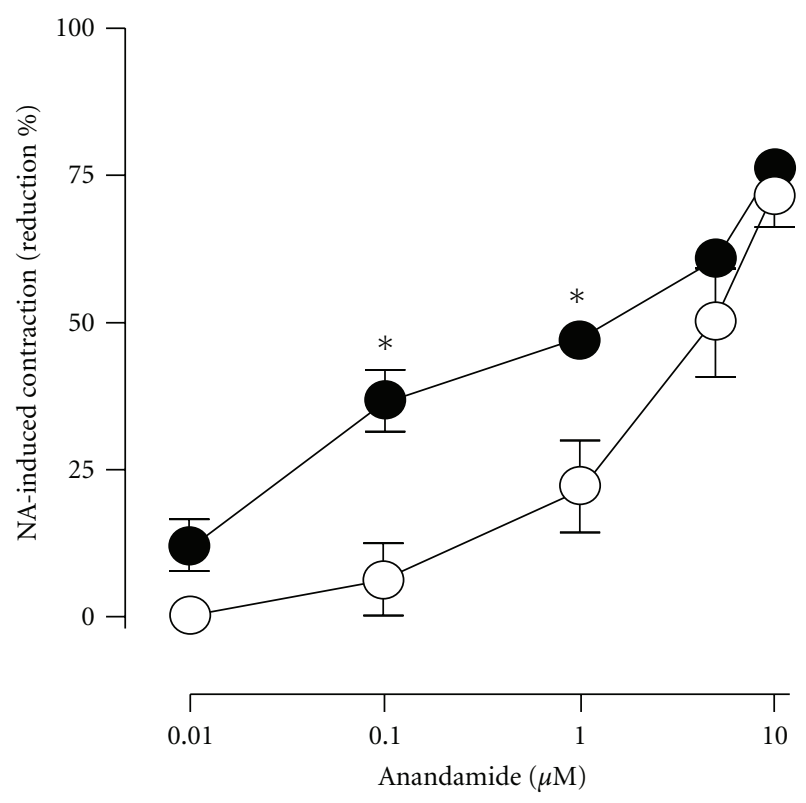

$20 \mathrm{mg} / \mathrm{kg}$ daidzein

(c)

FIGURE 3: Effects of 3-day administration of $10 \mathrm{mg} / \mathrm{kg}$ genistein in (a), $10 \mathrm{mg} / \mathrm{kg}$ daidzein in (b), and $20 \mathrm{mg} / \mathrm{kg}$ daidzein in (c) on the anandamide-induced reductions of contractile responses to NA in mesenteric beds isolated from ovariectomized female rats. Vehicles are depicted in open circles. ${ }^{*} P<0.05$ when treatments were compared to the corresponding vehicles.

hyperactivity in vascular tissues that usually precedes the onset of primary hypertension [12].

The observation that the anandamide-induced relaxations in the OVX rats were restored by a 3-day oral administration of phytoestrogens (present results) to the same extent as that produced by $17 \beta$-estradiol administration [16] suggests that a common site of action, namely, estrogen receptors (ER), could be involved in both cases. In support of this view is the finding that in intact as well as in OVX female rats the facilitatory effect of phytoestrogens was counteracted by the ER antagonist fulvestrant.

Moreover, a direct effect of phytoestrogens on the contractility to NA is precluded on the basis that no differences were observed in the responsiveness to NA between male 

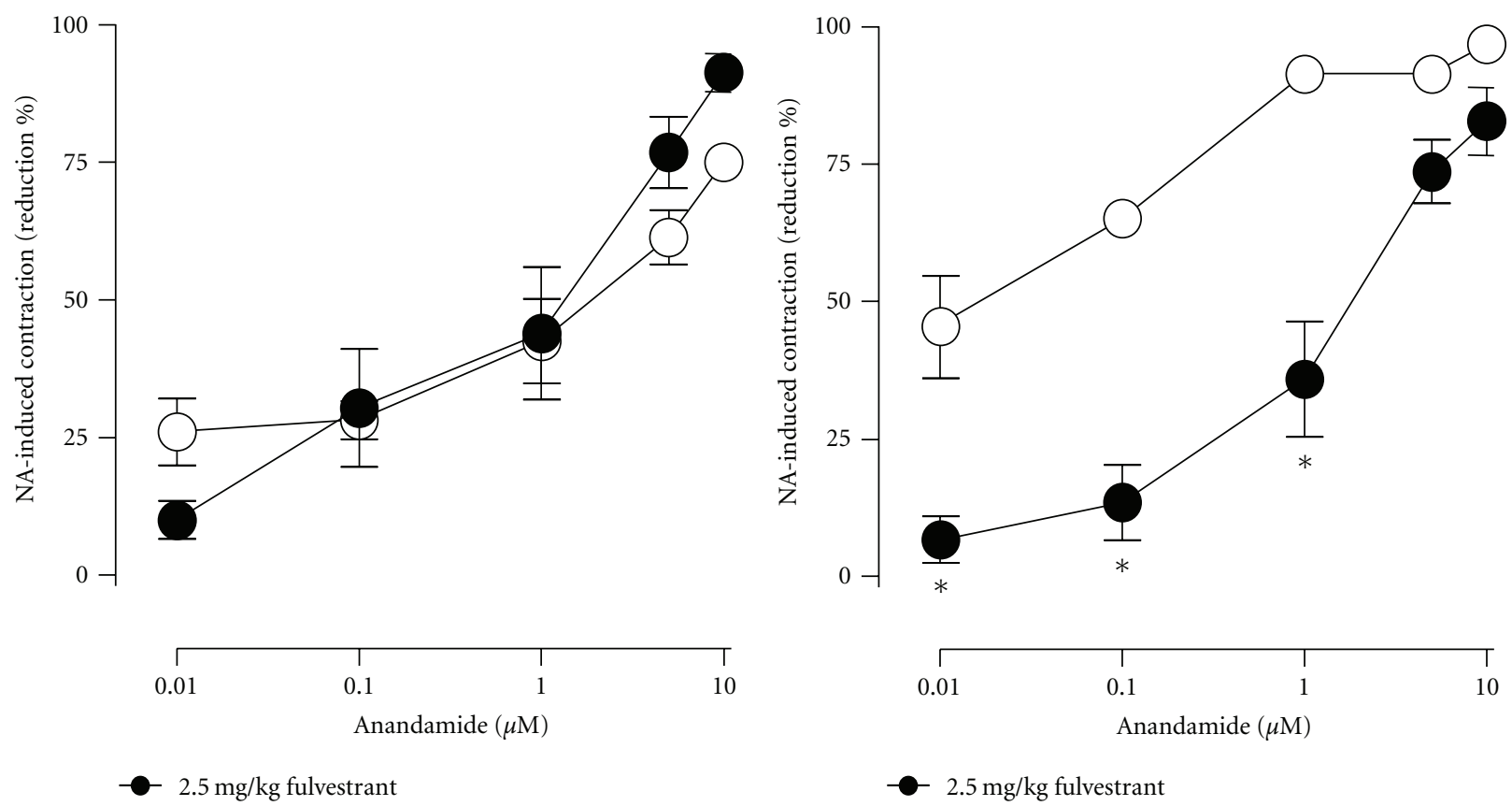

(b)

(a)

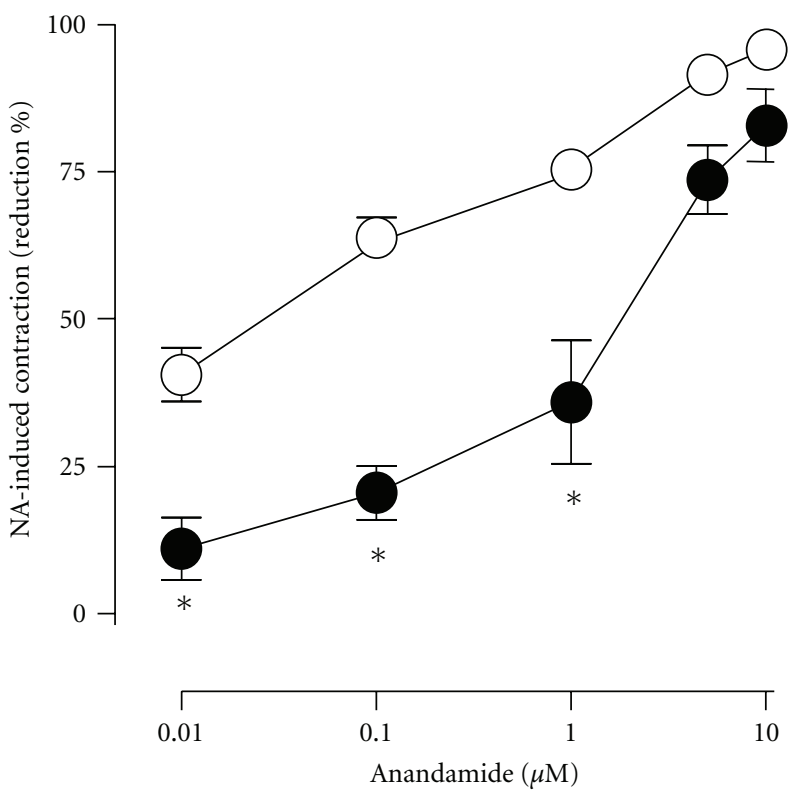

$2.5 \mathrm{mg} / \mathrm{kg}$ fulvestrant

(c)

FIGURE 4: Effects of 3-day s.c. administration of $2.5 \mathrm{mg} / \mathrm{kg}$ of fulvestrant on the anandamide-induced reductions of contractile responses to NA in untreated (a), genisteintreated $(10 \mathrm{mg} / \mathrm{kg}$; (b)), or daidzein-treated $(20 \mathrm{mg} / \mathrm{kg}$; (c)) intact female rats. Either fulvestrant (filled circles) or its vehicle (open circles) were administered concomitantly with the corresponding phytoestrogen treatment. ${ }^{*} P<0.05$ when phytoestrogen-treated were compared against phytoestrogen plus fulvestrant-treated intact female rats.

and age-matched female rats after treatment with genistein or daidzein ([16] and present results).

The fact that, as previously observed for $17 \beta$-estradiol [6], the 3-day oral treatment with either $10 \mathrm{mg} / \mathrm{kg}$ genistein or $20 \mathrm{mg} / \mathrm{kg}$ daidzein restored the decrease in the density of CGRP-containing perivascular fibers in mesenteries isolated from OVX rats could indicate that the modulation of CGRP levels contributes, among other factors, to the ability of phytoestrogens to potentiate the effect of anandamide in the mesenteric vasculature. In addition, this finding is supported on the basis that the presence of fulvestrant completely prevented the enhancing effect of phytoestrogens on CGRP 

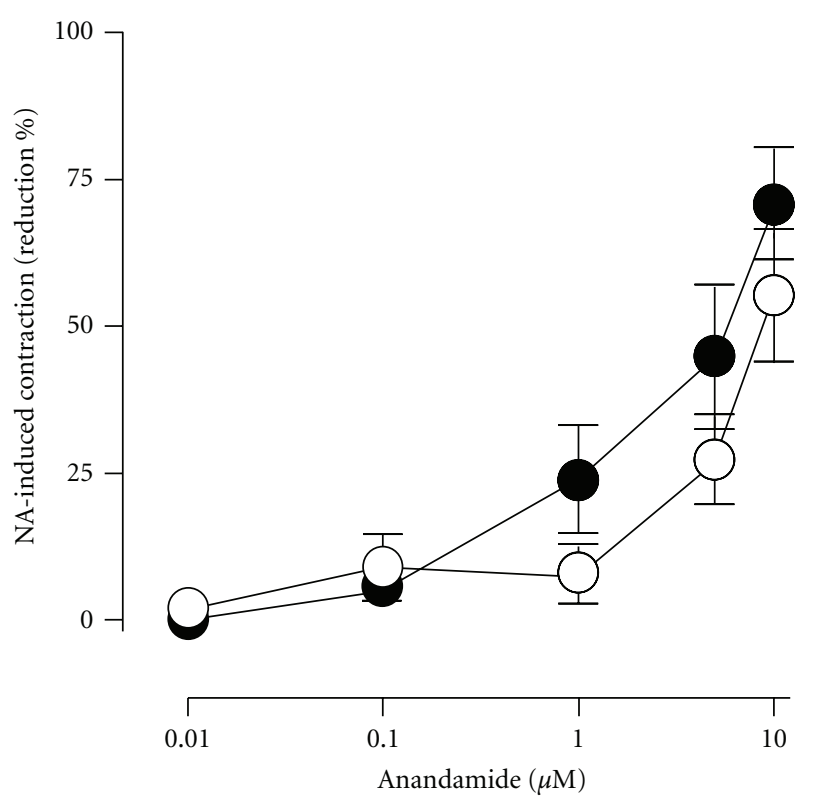

$2.5 \mathrm{mg} / \mathrm{kg}$ fulvestrant

(a)

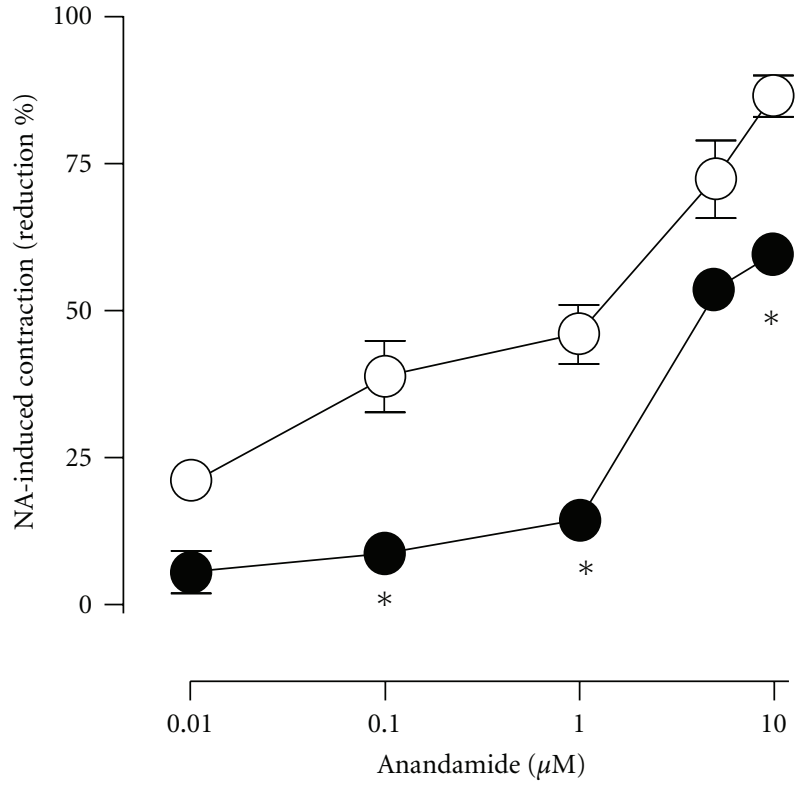

$2.5 \mathrm{mg} / \mathrm{kg}$ fulvestrant

(b)

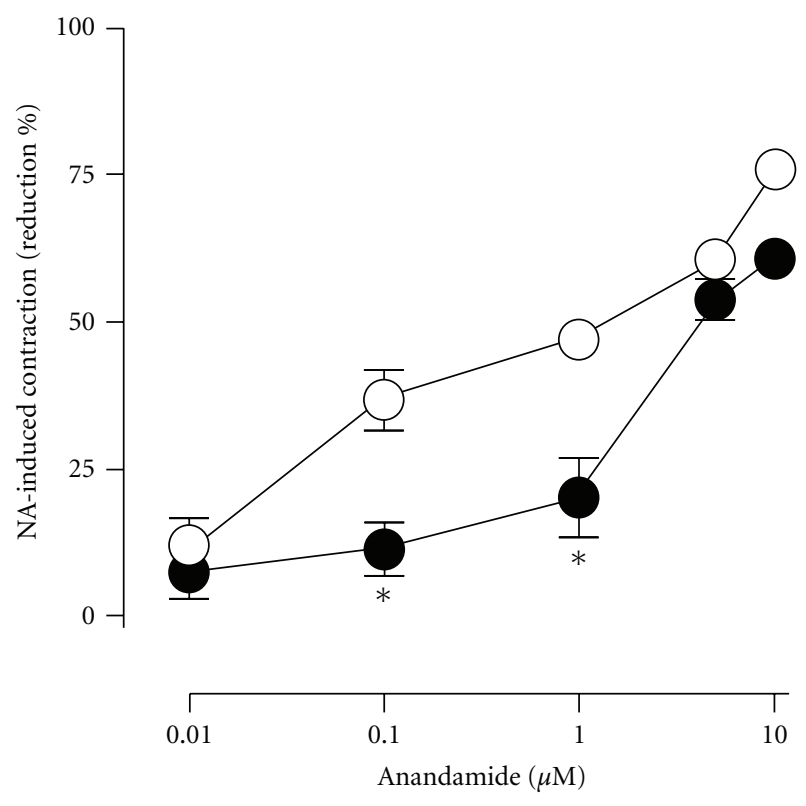

$2.5 \mathrm{mg} / \mathrm{kg}$ fulvestrant

(c)

FIGURE 5: Effects of 3-day s.c. administration of $2.5 \mathrm{mg} / \mathrm{kg}$ of fulvestrant on the anandamide-induced reductions of contractile responses to NA in untreated (a), genistein-treated $(10 \mathrm{mg} / \mathrm{kg}$; (b)), or daidzein-treated $(20 \mathrm{mg} / \mathrm{kg}$; (c)) OVX female rats. Fulvestrant (filled circles) or its vehicle (open circles) were concomitantly administered with the corresponding phytoestrogen treatment. ${ }^{*} P<0.05$ when phytoestrogentreated were compared against phytoestrogen plus fulvestrant-treated OVX female rats.

perivascular levels. This hypothesis agrees with previous evidence showing that mesenteric availability of CGRP underlies the ability of anandamide to reduce the contractile responses to NA in mesenteric arteries [6]. Similarly, a causeeffect relationship between estrogen levels and CGRP arises from the observation that CGRP-containing fibers density is faded after ovariectomy and restored by estradiol treatment in sensory and perivascular neurons $[6,19]$. Specifically related to phytoestrogens, it was reported that a diet with fujiflavone P40, a soybean isoflavone product, completely reverses the decrease in the levels of the mRNA coding for CGRP in dorsal root ganglion neurons, as well as the 

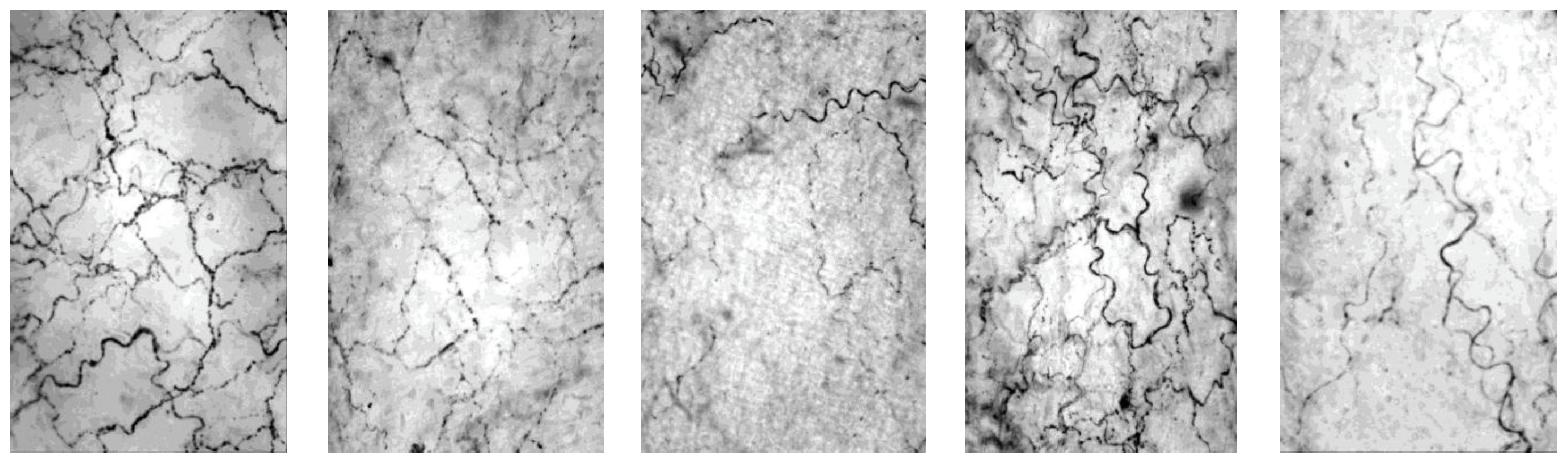

(a)

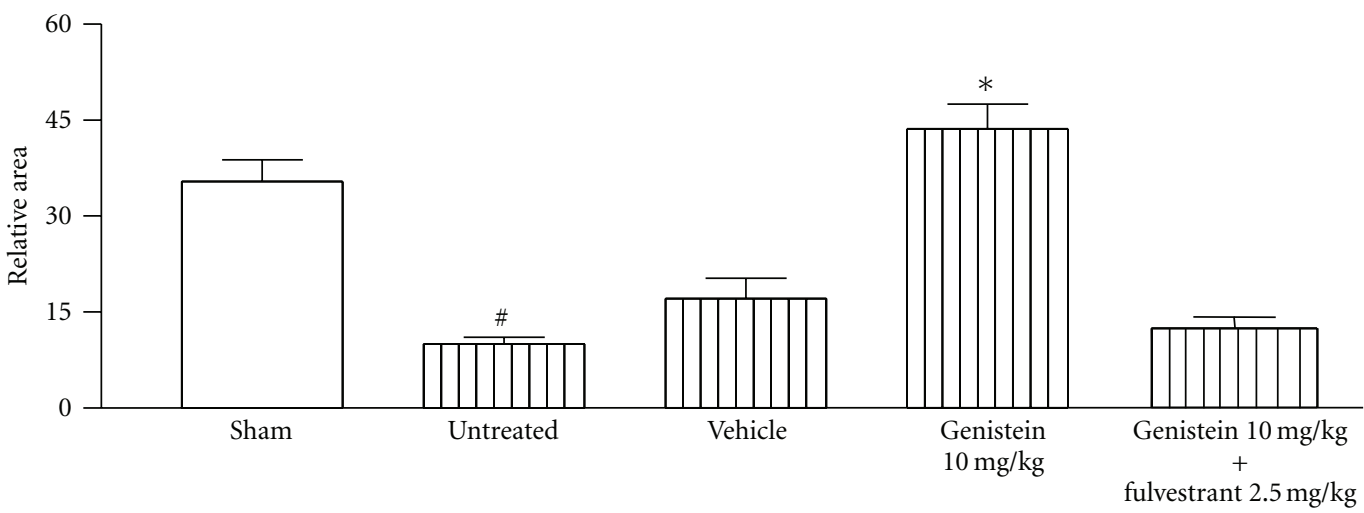

$\square$ Sham

피 OvX

(b)

FIGURE 6: Immunohistochemistry for CGRP. (a) Representative microphotographs of CGRP-immunoreactive fibers surrounding mesenteric arteries in myenteric plexus preparations of sham-operated as well as of OVX female rats. Either genistein ( $10 \mathrm{mg} / \mathrm{kg}$ p.o.) or genistein plus fulvestrant $(10 \mathrm{mg} / \mathrm{kg}$ p.o. and $2.5 \mathrm{mg} / \mathrm{kg}$ s.c., resp.) were administered daily during 3 days. The photomicrographs were captured at $400 \mathrm{x}$ magnification; the scale bar indicates $50 \mu \mathrm{m}$. (b) Bars represent the mean \pm SEM $(n=4)$ of relative morphometric units measured as stained area/total area. Specific immunoreactivity in every tissue was calculated as the difference between anti-CGRP-incubated and nonprimary antibody-incubated samples. ${ }^{*} P<0.001$ between sham and untreated-ovariectomized female rats. ${ }^{*} P<0.01$ between genistein-treated and either genistein plus fulvestrant-treated or the corresponding vehicle-treated OVX rats.

diminutions of the gastric tissue levels of CGRP in OVX rats [20]. In this sense, the lack of effect of oral treatment with $10 \mathrm{mg} / \mathrm{kg}$ daidzein agrees with the present observation that $10 \mathrm{mg} / \mathrm{kg}$ daidzein did not counteract the decrease in mesenteric CGRP content caused by OVX. This observation is consistent with previous evidence showing that genistein is 10 to 100 times more potent than daidzein and that this difference is linked to a higher affinity of genistein for ER [8], as observed for the modulation of the expression of enzymes that metabolize $17 \alpha$-estradiol in cultured MCF-7 cells [21].

On the other hand, the fact that phytoestrogens enhanced anandamide-induced effects selectively in the vasculature of female rats (present results) differs from the potentiation caused by $17 \beta$-estradiol in this tissue that is only observed in males [16]. This discrepancy could arise from the fact that the sex-related differences in the rat vasculature, which include variations in the density and distribution of ER subtypes [22], could only become evident when tissues are exposed to compounds, such as genistein and daidzein, that are known to possess a 1000-times lower estrogenic activity than estradiol and are supposed to act as ERbeta partial agonist [8]. In accordance to this, vasodilation to genistein but not to $17 \beta$-estradiol is enhanced in postmenopausal women suffering coronary heart disease that express high ERbeta in the vascular wall [23]. However, a more extensive analysis of the estrogen receptor subtypes involved in the vascular effects of anandamide, including variations in the density and distribution of ER subtypes in the mesenteric bed of male and female Sprague-Dawley rats, is necessary to reinforce this possibility.

Moreover, the lack of effect of phytoestrogens in males (present results) could rely on the fact that phytoestrogens modify male gonadal steroids levels $[24,25]$. In support of the latter, it was reported that the control of anxietyrelated behaviours produced by the systemic administration of phytoestrogens in male rats depends on the gonadal status [26].

At the molecular level, the fatty acid amidohydrolase (FAAH), the major anandamide-hydrolyzing enzyme, is a potential locus for an interaction between oestrogens 

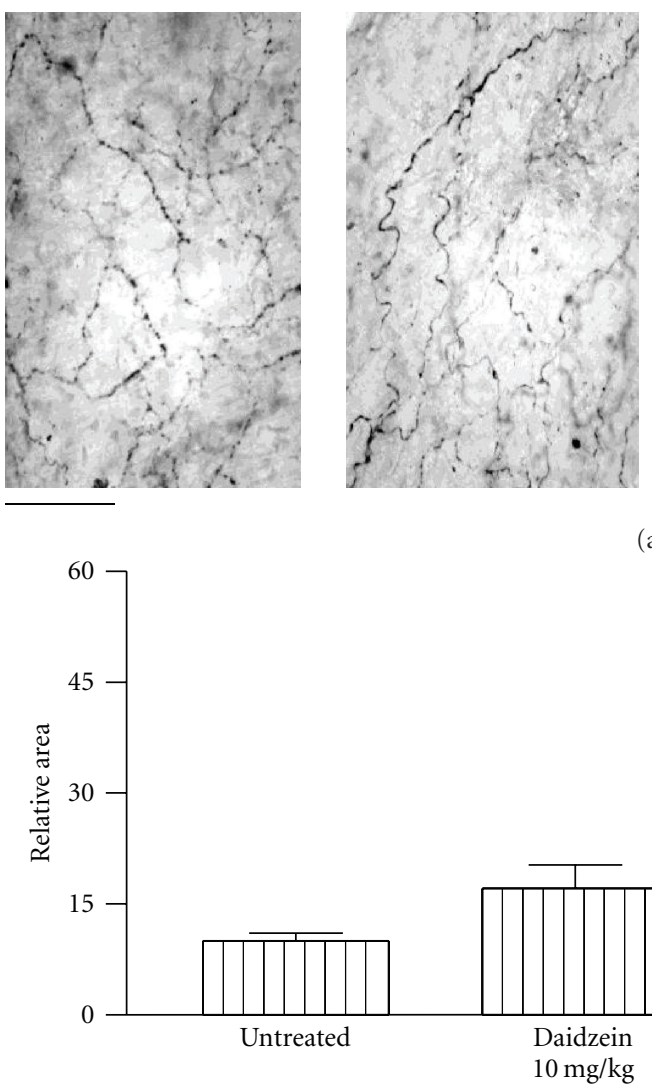
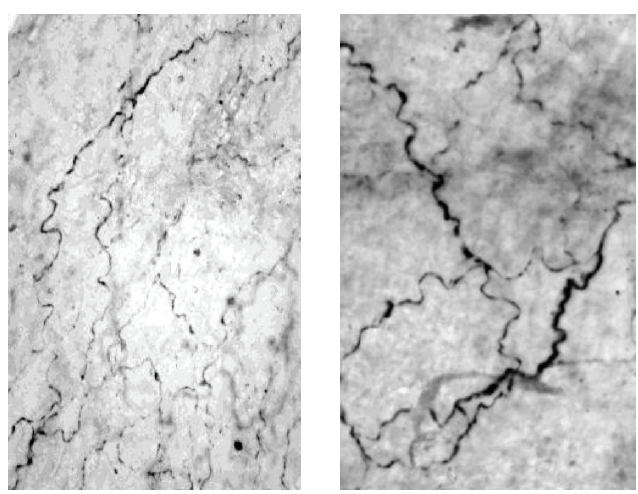

(a)

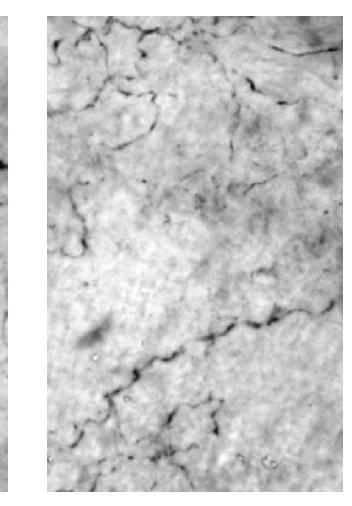


[2] A. J. Wheal, T. Bennett, M. D. Randall, and S. M. Gardiner, "Cardiovascular effects of cannabinoids in conscious spontaneously hypertensive rats," British Journal of Pharmacology, vol. 152, no. 5, pp. 717-724, 2007.

[3] Y. Wang, N. E. Kaminski, and D. H. Wang, "Endocannabinoid regulates blood pressure via activation of the transient receptor potential vanilloid type 1 in wistar rats fed a high-salt diet," Journal of Pharmacology and Experimental Therapeutics, vol. 321, no. 2, pp. 763-769, 2007.

[4] G. Godlewski, S. O. Alapafuja, S. Bátkai et al., "Inhibitor of fatty acid amide hydrolase normalizes cardiovascular function in hypertension without adverse metabolic effects," Chemistry and Biology, vol. 17, no. 11, pp. 1256-1266, 2010.

[5] M. Maccarrone, M. Bari, N. Battista, and A. Finazzi-Agrò, "Estrogen stimulates arachidonoylethanolamide release from human endothelial cells and platelet activation," Blood, vol. 100, no. 12, pp. 4040-4048, 2002.

[6] R. N. Peroni, M. L. Orliac, T. Abramoff, M. L. Ribeiro, A. M. Franchi, and E. Adler-Graschinsky, "Participation of CGRP and prostanoids in the sex-linked differences of vascular anandamide effects in mesenteric beds of Sprague-Dawley rats," European Journal of Pharmacology, vol. 557, no. 1, pp. 49-57, 2007.

[7] P. M. Zygmunt, J. Petersson, D. A. Andersson et al., "Vanilloid receptors on sensory nerves mediate the vasodilator action of anandamide," Nature, vol. 400, no. 6743, pp. 452-457, 1999.

[8] G. G. J. M. Kuiper, J. G. Lemmen, B. Carlsson et al., "Interaction of estrogenic chemicals and phytoestrogens with estrogen receptor $\beta$," Endocrinology, vol. 139, no. 10, pp. 42524263, 1998.

[9] M. J. J. de Kleijn, Y. T. van der Schouw, P. W. F. Wilson, D. E. Grobbee, and P. F. Jacques, "Dietary intake of phytoestrogens is associated with a favorable metabolic cardiovascular risk profile in postmenopausal U.S. women: the framingham study," Journal of Nutrition, vol. 132, no. 2, pp. 276-282, 2002.

[10] A. E. Lethaby, J. Brown, J. Marjoribanks, F. Kronenberg, H. Roberts, and J. Eden, "Phytoestrogens for vasomotor menopausal symptoms," Cochrane Database of Systematic Reviews, no. 4, p. CD001395, 2007.

[11] L. Thors, J. Eriksson, and C. J. Fowler, "Inhibition of the cellular uptake of anandamide by genistein and its analogue daidzein in cells with different levels of fatty acid amide hydrolase-driven uptake," British Journal of Pharmacology, vol. 152, no. 5, pp. 744-750, 2007.

[12] D. D. P. Lee, V. DeQuattro, G. C. Davison, S. Kimura, R. Barndt, and P. Sullivan, "Noradrenergic hyperactivity in primary hypertension; central and peripheral markers of both behavioral pathogenesis and efficacy of sympatholytic and relaxation therapy," Clinical and Experimental HypertensionPart A, vol. 10, no. 1, pp. 225-234, 1988.

[13] R. C. M. Siow, F. Y. L. Li, D. J. Rowlands, P. de Winter, and G. E. Mann, "Cardiovascular targets for estrogens and phytoestrogens: transcriptional regulation of nitric oxide synthase and antioxidant defense genes," Free Radical Biology and Medicine, vol. 42, no. 7, pp. 909-925, 2007.

[14] P. Siriviriyakul, S. Khemapech, K. Monsiri, and S. Patumraj, "The vascular effect of genistein: what is its mechanism, nitric oxide or PGI2?" Clinical Hemorheology and Microcirculation, vol. 34, no. 1-2, pp. 97-101, 2006.

[15] P. Diel, R. B. Geis, A. Caldarelli et al., "The differential ability of the phytoestrogen genistein and of estradiol to induce uterine weight and proliferation in the rat is associated with a substance specific modulation of uterine gene expression,"
Molecular and Cellular Endocrinology, vol. 221, no. 1-2, pp. 2132, 2004.

[16] R. N. Peroni, M. L. Orliac, D. Becu-Villalobos, J. P. HuidobroToro, E. Adler-Graschinsky, and S. M. Celuch, "Sex-linked differences in the vasorelaxant effects of anandamide in vascular mesenteric beds: role of oestrogens," European Journal of Pharmacology, vol. 493, no. 1-3, pp. 151-160, 2004.

[17] V. E. Mendizabal, E. C. Feleder, and E. Adler-Granschinsky, "Effects of the chronic in vivo administration of L-NAME on the contractile responses of the rat perfused mesenteric bed," Journal of Autonomic Pharmacology, vol. 19, no. 4, pp. 241$248,1999$.

[18] K. L. Christensen and M. J. Mulvany, "Mesenteric arcade arteries contribute substantially to vascular resistance in conscious rats," Journal of Vascular Research, vol. 30, no. 2, pp. 73-79, 1993.

[19] G. R. Ross, U. Yallampalli, P. R. R. Gangula et al., "Adrenomedullin relaxes rat uterine artery: mechanisms and influence of pregnancy and estradiol," Endocrinology, vol. 151, no. 9, pp. 4485-4493, 2010.

[20] N. Shimozawa, K. Okajima, and N. Harada, "Estrogen and isoflavone attenuate stress-induced gastric mucosal injury by inhibiting decreases in gastric tissue levels of CGRP in ovariectomized rats," American Journal of PhysiologyGastrointestinal and Liver Physiology, vol. 292, no. 2, pp. G615G619, 2007.

[21] J. Wagner, L. Jiang, and L. Lehmann, "Phytoestrogens modulate the expression of $17 \alpha$-estradiol metabolizing enzymes in cultured MCF-7 cells," Advances in Experimental Medicine and Biology, vol. 617, pp. 625-632, 2008.

[22] D. A. Smiley and R. A. Khalil, "Estrogenic compounds, estrogen receptors and vascular cell signaling in the aging blood vessels," Current Medicinal Chemistry, vol. 16, no. 15, pp. 1863-1887, 2009.

[23] M. N. Cruz, S. Agewall, K. Schenck-Gustafsson, and K. Kublickiene, "Acute dilatation to phytoestrogens and estrogen receptor subtypes expression in small arteries from women with coronary heart disease," Atherosclerosis, vol. 196, no. 1, pp. 49-58, 2008.

[24] K. D. Hancock, E. S. Coleman, Y. X. Tao et al., "Genistein decreases androgen biosynthesis in rat Leydig cells by interference with luteinizing hormone-dependent signaling," Toxicology Letters, vol. 184, no. 3, pp. 169-175, 2009.

[25] D. Gunnarsson, G. Selstam, Y. Ridderstråle, L. Holm, E. Ekstedt, and A. Madej, "Effects of dietary phytoestrogens on plasma testosterone and triiodothyronine (T3) levels in male goat kids," Acta veterinaria Scandinavica, vol. 51, p. 51, 2009.

[26] H. B. Patisaul, K. T. Burke, R. E. Hinkle, H. B. Adewale, and D. Shea, "Systemic administration of diarylpropionitrile (DPN) or phytoestrogens does not affect anxiety-related behaviors in gonadally intact male rats," Hormones and Behavior, vol. 55, no. 2, pp. 319-328, 2009.

[27] N. S. Waleh, B. F. Cravatt, A. Apte-Deshpande, A. Terao, and T. S. Kilduff, "Transcriptional regulation of the mouse fatty acid amide hydrolase gene," Gene, vol. 291, no. 1-2, pp. 203-210, 2002.

[28] C. G. Reich, M. E. Taylor, and M. M. McCarthy, "Differential effects of chronic unpredictable stress on hippocampal CB1 receptors in male and female rats," Behavioural Brain Research, vol. 203, no. 2, pp. 264-269, 2009. 


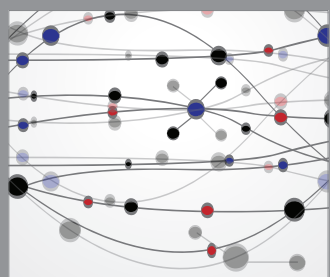

The Scientific World Journal
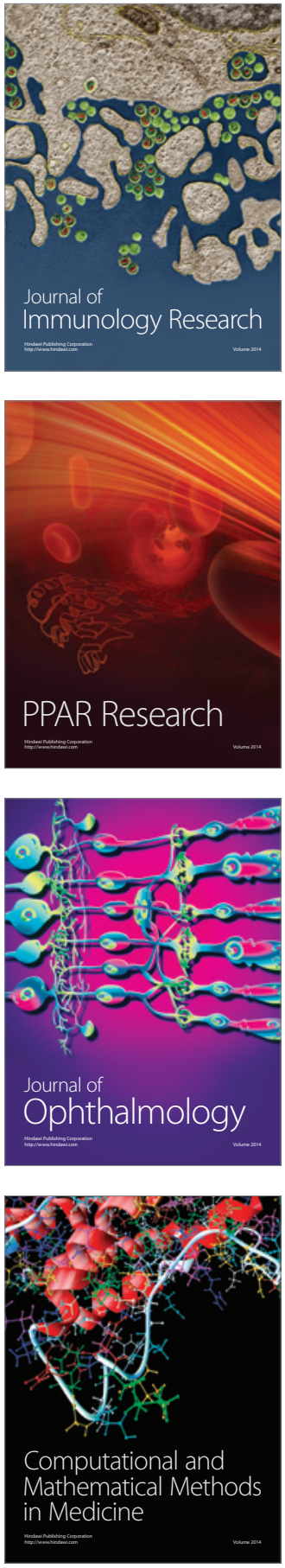

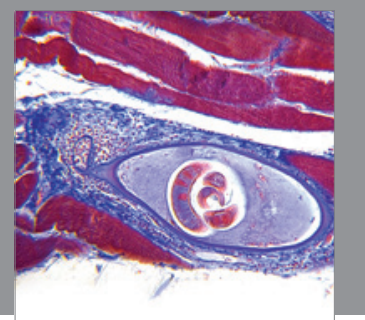

Gastroenterology

Research and Practice
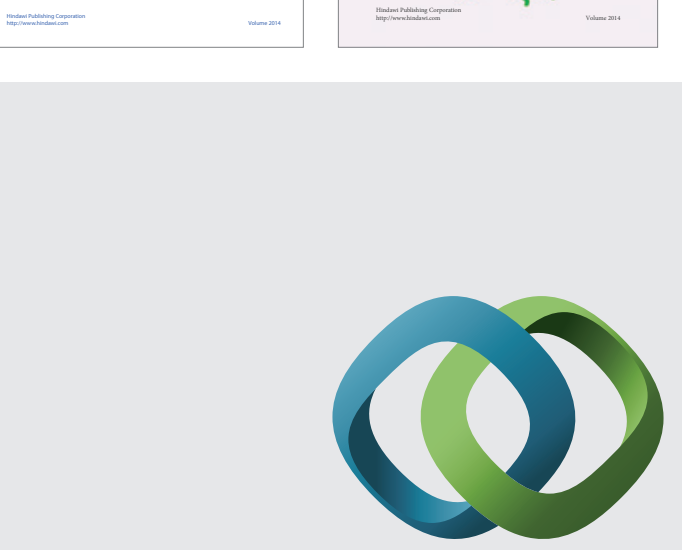

\section{Hindawi}

Submit your manuscripts at

http://www.hindawi.com
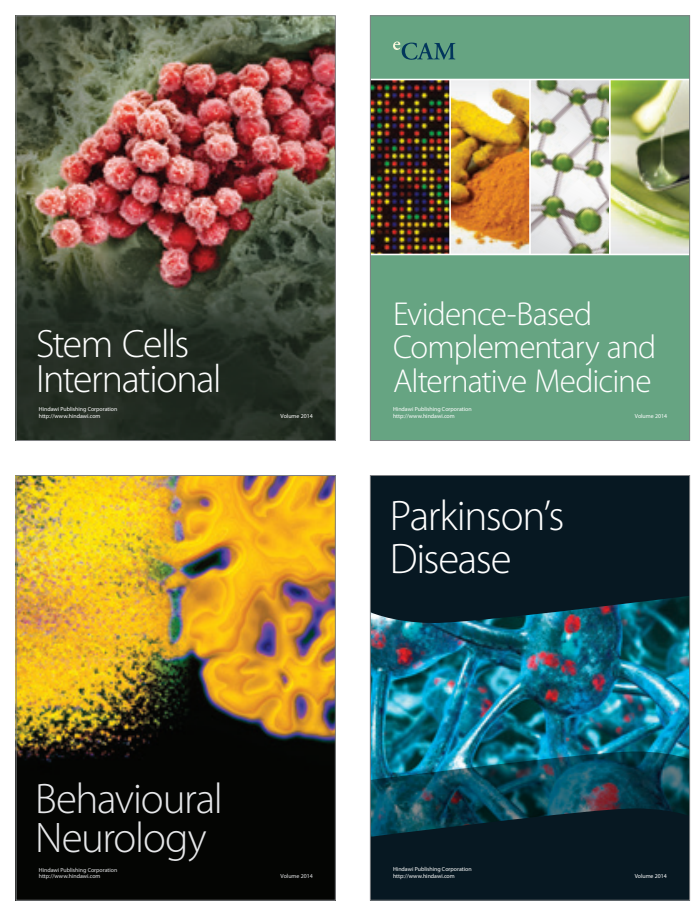

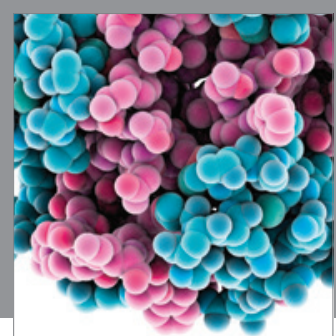

Journal of
Diabetes Research

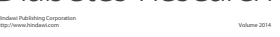

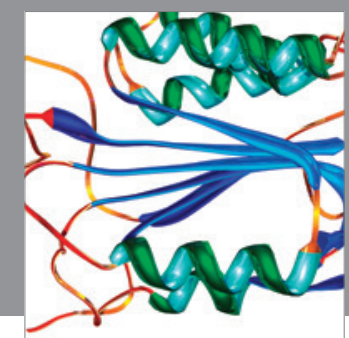

Disease Markers
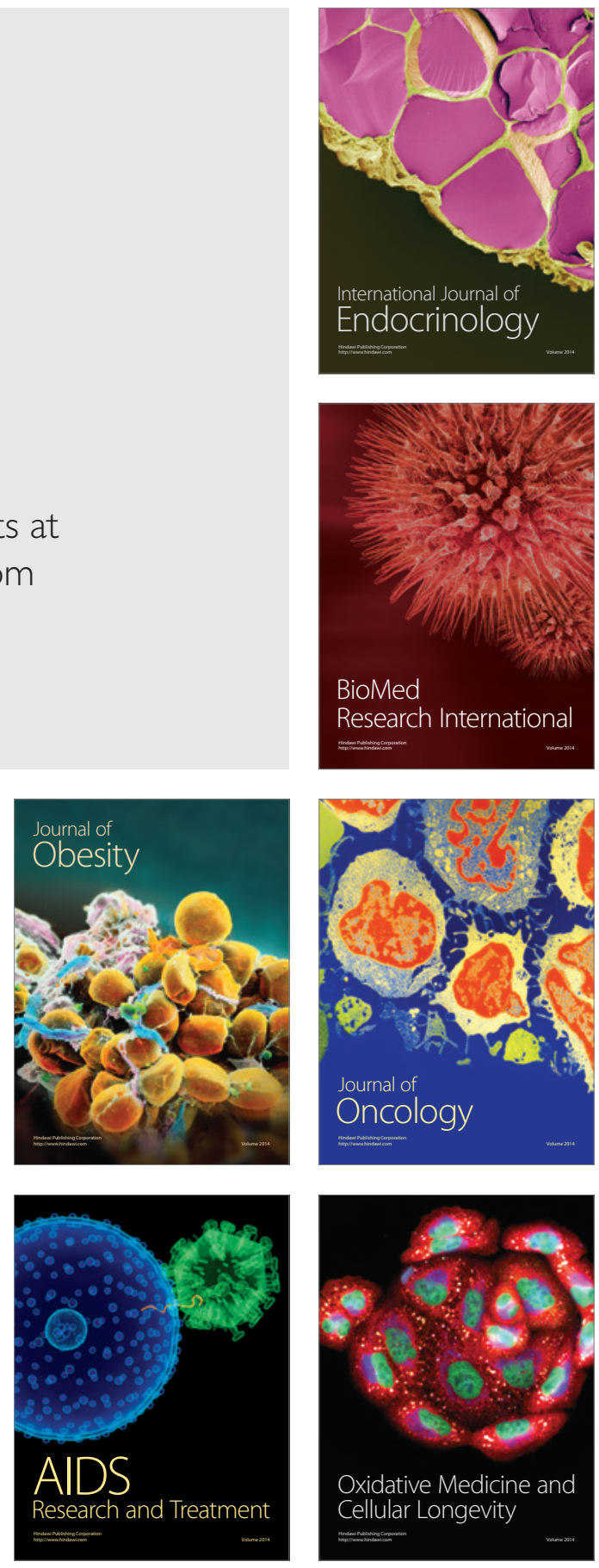